\title{
A transcriptomics study on hepatic lipid metabolism in mice exposed to contaminated drinking water
}

\author{
J. Yin $\cdot$ F. Zhao $\cdot$ X.-X. Zhang $\cdot$ Y. Chen $\cdot$ \\ W. Li $\cdot$ B. Wu $\cdot$ H. Ren
}

Received: 3 February 2013/Revised: 30 August 2013/Accepted: 3 November 2013/Published online: 26 November 2013

(C) Islamic Azad University (IAU) 2013

\begin{abstract}
DNA microarray was used to analyze hepatic transcriptional profile of male mice (Mus musculus) after the mice were fed with Yangtze River (China) source water (NJS) and tap water (NJT) for 90 days. Chemical analysis demonstrated that NJS and NJT contained various tracelevel pollutants including polycyclic aromatic hydrocarbons, phthalate ethers and inorganic contaminants. DNA microarray revealed occurrence of 5,042 differentially expressed genes (DEGs) in the mice fed with NJS and 828 DEGs in the mice fed with NJT, indicating that NJS posed greater influence on liver transcriptome. Annotation against Kyoto Encyclopedia of Genes and Genomes pathway database showed that the DEGs in NJS group were mostly involved in lipid metabolism (51 DEGs), followed by neurodegenerative diseases (47 DEGs), energy metabolism (41 DEGs) and endocrine system (38 DEGs). NJT exposure was found to affect lipid metabolism (14 DEGs), xenobiotics biodegradation and metabolism (6 DEGs), and cofactors and vitamins metabolism (5 DEGs). Annotation against Gene Ontology database confirmed that lipid metabolism among the altered pathways was most
\end{abstract}

Electronic supplementary material The online version of this article (doi:10.1007/s13762-013-0424-8) contains supplementary material, which is available to authorized users.

J. Yin · F. Zhao $\cdot$ X.-X. Zhang $(\bowtie) \cdot$ Y. Chen $\cdot$ B. Wu $\cdot$ H. Ren State Key Laboratory of Pollution Control and Resource Reuse, School of the Environment, Nanjing University, 163 Xianlin Road, Nanjing 210023, China

e-mail: zhangxx@nju.edu.cn

W. Li

Nanjing Institute of Environmental Sciences, Ministry of Environmental Protection of China, 8 Jiangwangmiao Street, Nanjing 210042, China susceptible to both NJS and NJT exposure. The DEGs were involved in 6 lipid metabolic pathways including fatty acid metabolism, glycerophospholipid metabolism, unsaturated fatty acid biosynthesis, steroid biosynthesis, primary bile acid biosynthesis and steroid hormone biosynthesis. Although both NJS and NJT might cause no obvious liver tissue damages, the lipid metabolic disturbance induced by trace-level pollutants still deserves public health concern.

Keywords Drinking water - Environmental pollution . Genomic toxicity $\cdot$ Lipid metabolism · Microarray

\section{Introduction}

Recently, drinking water safety has received great concern, since growing evidence indicates that long-term exposure to contaminated drinking water can induce carcinogenicity (Keshavarzi et al. 2012), genotoxicity (Rebola et al. 2011), and developmental (Kozul-Horvath et al. 2012) and reproductive toxicities (Welsch et al. 2008). Yangtze River is the longest river in China, and the river basin supports one-third of China's population and contributes about $40 \%$ of the national gross domestic product of China (Zhang et al. 2009). As a result of economic development, wastewater discharge into the river has been increasing in recent years, reaching annual $3.2 \times 10^{10}$ tons of domestic sewage and industrial wastewater (CWRC 2011).

Yangtze River provides source of drinking water for most cities along the river, but various pollutants, including polycyclic aromatic hydrocarbons (PAHs) (Chen et al. 2012), polychlorinated biphenyls (Yang et al. 2012) and heavy metals (Lin et al. 2012), are emerging in this river. Most of these pollutants in the river water are present at 
trace levels, but they can be easily bio-accumulated in aquatic food chains (Yi and Zhang 2012) and induce toxicities on humans and wildlife (Axmon et al. 2008).

Liver functions can be disturbed by various organic pollutants present in drinking water, such as PAHs (Oh et al. 2012) and phthalate esters (PAEs) (Maranghi et al. 2010). It is known that liver plays a central role in lipid metabolism and constitutes the major site of lipogenesis and lipolysis (Nguyen et al. 2008). Furthermore, liver can take up and degrade various types of lipoproteins, and an imbalance between the lipid availability and disposal may result in hepatic lipid accumulation, eventually causing lipoperoxidative stress and hepatic injury (Bechmann et al. 2012). Great efforts have been devoted to screening or developing potential inhibitor of hepatic lipid accumulation for clinical applications (Silverio et al. 2012). Unfortunately, few studies currently focus on the effects of drinking water on hepatic lipid metabolism, although it has been indicated that some pollutants (e.g., PAHs and cadmium) can disturb lipid metabolism (Larregle et al. 2008; Podechard et al. 2012).

DNA microarray is considered as a promising genomic profiling technique characterized with high throughput, high speed and high sensitivity, which has been used to evaluate the toxicities of environmental samples, including source water (Wu et al. 2009), drinking water (Shi et al. 2012), industrial effluent (Zhang et al. 2010) and sediments (Kosmehl et al. 2012). In this study, we used DNA microarray to evaluate hepatic genomic toxicity on mice sub-chronically exposed to source water (NJS) and tap water (NJT) from Yangtze River, focusing on exploring the potential molecular pathways mediating the lipid metabolism disturbance. The whole research was carried out at the Nanjing University and the General Hospital of Nanjing Military Command (Nanjing City, China) during September 2011 to December 2012. Results of this study might extend our knowledge about the potential effects of drinking water on hepatic lipid metabolism.

\section{Materials and methods}

Sample collection

NJS and NJT were sampled in September 2011 from BHK Tap Water Plant (Nanjing, China) with Yangtze River as source of tap water $\left(\mathrm{N} 32.05^{\circ}\right.$, E $\left.118.72^{\circ}\right)$. In the plant, drinking water undergoes coagulation, sand filtration and chlorine disinfection before entering into pipeline distribution system. NJS was sampled from the influent of coagulation tank, and NJT was sampled from the effluent of chlorination tank. Water samples (10 L each) were collected in sterile brown glass bottles, and they were filtered through $0.45-\mu \mathrm{m}$ micropore membrane filter and kept at $4{ }^{\circ} \mathrm{C}$ before chemical analysis and animal exposure.

Chemical analysis

A total of 24 organic pollutants including PAHs, PAEs, organochlorine compounds and dinitrotoluenes in NJS and NJT were measured by using DSQ II Single Quadrupole GC/MS (ThermoQuest, San Jose, CA, USA). Details about the chemical analysis were previously described (Chen et al. 2012). Inorganic contaminants in the water samples were detected using ICP-J-A1100 (Jarell-Ash Inc., USA) following the methods of $\mathrm{Wu}$ et al. (2009).

Animal treatment

Animal exposure assay was performed at the General Hospital of Nanjing Military Command (China) during September to December 2011. A total of 30 five-week-old male mice (Mus musculus, KM, body weight 18-22 g) provided by the Animal Center of Academy of Military Medical Sciences Laboratory were housed individually in stainless steel cages under the controlled conditions (22 $\pm 2{ }^{\circ} \mathrm{C}$ temperature, $50 \pm 5 \%$ humidity, 12/12-h light dark cycle). After acclimated to the environmental conditions for 1 week, all the mice were randomly divided into three groups (10 mice each): The control group fed with purified water (Millipore Inc., MA, USA), the NJS group fed with source water, and the NJT group fed with tap water. All the mice had free access to sterile food and water during the exposure period. All the mice were treated for 90 days. The mice were treated humanely according to National Institutes of Health Guide for the Care and Use of Laboratory Animals (China), and the protocols were approved by the Animal Care and Use Committee of the General Hospital of Nanjing Military Command.

\section{RNA extraction}

After 90 days of exposure, all mice were anesthetized with diethyl ether and were then killed by eyeball blooding. Liver samples were cut into small pieces and stored in RNAlater (Takara, Japan) at $-80^{\circ} \mathrm{C}$. Total RNA from each liver was extracted by using TRIzol reagent (Invitrogen, USA) and purified by Qiagen RNeasy MiniRNA Cleanup Kit (Qiagen, Valencia, CA, USA) according to the Affymetrix (Affymetrix, CA, USA) recommended protocol. The concentration and quality of the extracted RNA were determined with Nanodrop 2000 (Thermo Scientific, DE, USA). RNA samples with $28 \mathrm{~S}: 18 \mathrm{~S}$ rRNA ratio of about $2: 1$ and $260 / 280 \mathrm{~nm}$ absorbance ratio of more than 1.8 were used for genomic expression analysis. 


\section{DNA microarray}

GeneChip $^{\circledR}$ Mouse Exon 1.0 ST Arrays (Affymetrix, USA) were used to determine the genomic toxicities of NJS and NJT according to the Affymetrix recommended protocol. Each of the 28,853 genes is represented on the array by approximately 27 probes spread across the full length of the gene, providing a more complete and an accurate picture of gene expression. Equal amount of RNA from the individuals of the same group was pooled together to eliminate inter-individual variations. In order to compare the alterations of the genes expressions, the treated and controlled samples were hybridized separately into a total of nine genechips (the microarrays were conducted in triplicate for each group). Details about the microarray detection were previously described by Zhang et al. (2010). After hybridization, the cocktail was removed and the arrays were washed and stained in Genechip_Fluidics Station 450 (Affymetrix, CA, USA) and scanned on the Genechip_Scanner 3000 7G (Affymetrix, CA, USA). Image analysis and probe quantification were performed by the Genechip_Operating Software (Affymetrix, CA, USA).

Data analysis

Normalization and comparison analysis of probe values were performed by Expression Console software (Affymetrix, USA). The data were analyzed by Partek Discovery Suite (Partek Inc., St. Louis, MO, USA) with a false discovery rate (FDR) cutoff of 0.1 . The fold changes in gene expression levels were represented as the ratio of the mean expression values from the treated and control groups. Genes with a fold change of more than \pm 2.0 and $p$ value of $<0.05$ were selected as the differentially expressed genes (DEGs) (Shi et al. 2012).

Biological significances of DEGs were analyzed on the basis of Gene Ontology (GO) database (http://www. geneontology.org/). DEGs were grouped into different biological pathways according to Kyoto Encyclopedia of Genes and Genomes (KEGG) pathway database (http:// www.genome.ad.jp/kegg/pathway.html). The biological pathways with more than 3 DEGs $(p<0.05)$ were considered to be significantly altered (Currie et al. 2005).

\section{Results and discussion}

Chemical analysis, water intake and liver weight index

Among the chemicals tested in this study, a total of 11 organic compounds including PAEs and PAHs, as well as 12 inorganic contaminants, were detectable in NJS and NJT (Table 1). The total concentration of organic compounds and inorganic
Table 1 The concentrations of organic compounds and inorganic contaminants in the source water (NJS) and drinking water (NJT)

\begin{tabular}{|c|c|c|c|}
\hline Pollutants & NJS & NJT & Standard \\
\hline $\begin{array}{l}\text { Diethyl phthalate } \\
\left(\text { ng L L }^{-1}\right)\end{array}$ & $37.54 \pm 0.91$ & $38.99 \pm 1.55$ & $<300$ \\
\hline $\begin{array}{l}\text { Di-N-butyl phthalate } \\
\left(\text { ng L }^{-1}\right)\end{array}$ & $51.67 \pm 3.42$ & $70.06 \pm 13.98$ & $<3.0$ \\
\hline $\begin{array}{l}\text { Diethylhexyl } \\
\text { phthalate }\left(\mathrm{ng} \mathrm{L}^{-1}\right)\end{array}$ & $80.33 \pm 2.24$ & $76.74 \pm 1.87$ & N. \\
\hline $\begin{array}{l}\text { Bis-2-ethylhexyl } \\
\text { adipate }\left(\mathrm{ng} \mathrm{L}^{-1}\right)\end{array}$ & $79.11 \pm 0.73$ & $77.98 \pm 2.47$ & $<8.0$ \\
\hline $\begin{array}{l}\text { Benzyl butyl } \\
\text { phthalate }\left(\mathrm{ng} \mathrm{L}^{-1}\right)\end{array}$ & $92.11 \pm 10.82$ & $86.66 \pm 2.93$ & N. \\
\hline $\begin{array}{l}\text { Dimethyl phthalate } \\
\left(\mathrm{ng} \mathrm{L}^{-1}\right)\end{array}$ & $49.41 \pm 0.81$ & $49.52 \pm 0.58$ & N. \\
\hline $\begin{array}{l}\text { Hexachlorobenzene } \\
\left(\text { ng L L }^{-1}\right)\end{array}$ & N.D. & $53.74 \pm 31.68$ & $<6.0$ \\
\hline Anthracene $\left(\right.$ ng L $\left.^{-1}\right)$ & $23.69 \pm 1.70$ & $22.94 \pm 0.47$ & $\mathrm{~N}$. \\
\hline $\begin{array}{l}\text { Phenanthrene } \\
\left(\text { ng L L }^{-1}\right)\end{array}$ & $25.23 \pm 1.43$ & $24.15 \pm 0.97$ & N. \\
\hline Isophorone (ng L ${ }^{-1}$ ) & $51.25 \pm 25.61$ & $16.33 \pm 0.80$ & N. \\
\hline $\begin{array}{l}\text { Acenaphthylene } \\
\left(\text { ng L L }^{-1}\right)\end{array}$ & $6.59 \pm 5.71$ & N.D. & N. \\
\hline $\mathrm{Al}\left(\mathrm{mg} \mathrm{L}^{-1}\right)$ & $0.011 \pm 0.002$ & $0.036 \pm 0.010$ & $<0.2$ \\
\hline $\mathrm{Ba}\left(\mathrm{mg} \mathrm{L}^{-1}\right)$ & $0.038 \pm 0.001$ & $0.059 \pm 0.001$ & $<0.7$ \\
\hline $\mathrm{Ca}\left(\mathrm{mg} \mathrm{L}^{-1}\right)$ & $44.267 \pm 0.723$ & $39.633 \pm 0.896$ & N. \\
\hline $\mathrm{Cr}\left(\mathrm{mg} \mathrm{L}^{-1}\right)$ & $0.005 \pm 0.002$ & $0.004 \pm 0.000$ & $<0.06$ \\
\hline $\mathrm{Cu}\left(\mathrm{mg} \mathrm{L}^{-1}\right)$ & $0.002 \pm 0.000$ & $0.002 \pm 0.000$ & $<1.0$ \\
\hline $\mathrm{K}\left(\mathrm{mg} \mathrm{L}^{-1}\right)$ & $7.543 \pm 0.095$ & $2.537 \pm 0.068$ & N. \\
\hline $\mathrm{Mg}\left(\mathrm{mg} \mathrm{L}^{-1}\right)$ & $19.133 \pm 0.306$ & $8.717 \pm 0.032$ & N. \\
\hline $\mathrm{Na}\left(\mathrm{mg} \mathrm{L}^{-1}\right)$ & $77.367 \pm 1.405$ & $16.000 \pm 0.100$ & $<200$ \\
\hline $\mathrm{P}\left(\mathrm{mg} \mathrm{L}^{-1}\right)$ & $0.074 \pm 0.020$ & $0.056 \pm 0.018$ & N. \\
\hline $\mathrm{Si}\left(\mathrm{mg} \mathrm{L}^{-1}\right)$ & $5.483 \pm 0.542$ & $3.947 \pm 0.091$ & N. \\
\hline $\operatorname{Sr}\left(\mathrm{mg} \mathrm{L}^{-1}\right)$ & $0.237 \pm 0.006$ & $0.240 \pm 0.000$ & N. \\
\hline $\mathrm{Zn}\left(\mathrm{mg} \mathrm{L}^{-1}\right)$ & N.D. & $0.029 \pm 0.006$ & $<1.0$ \\
\hline
\end{tabular}

N.D. not detectable

Standard: corresponding limits for the contaminants allowed in drinking water according to Standard of Drinking Water Quality of China

$N$. no corresponding limit is available for the contaminant in Standard of Drinking Water Quality of China

contaminants was $496.93 \mathrm{ng} \mathrm{L}^{-1}$ and $154.16 \mathrm{mg} \mathrm{L}^{-1}$ in NJS and $517.11 \mathrm{ng} \mathrm{L}^{-1}$ and $71.26 \mathrm{mg} \mathrm{L}^{-1}$ in NJT, respectively. Several PAEs including diethyl phthalate, dibutyl phthalate, di 2-ethyl hexyl phthalate, butyl benzyl phthalate and dimethyl phthalate were present in the water, among which butyl benzyl phthalate had the highest concentration, reaching $92.11 \mathrm{ng} \mathrm{L}^{-1}$ in NJS and $86.66 \mathrm{ng} \mathrm{L}^{-1}$ in NJT. A great number of large-scale petrochemical and chemical engineering industries are located along Yangtze River at Nanjing section, and plenty of adhesives, glues, electronics, agricultural adjuvants, building materials, pharmaceuticals and medical devices are produced in this region, which may 
account for the high level of the phthalates in the water samples. The main metallic elements in the source water and drinking water included $\mathrm{Na}, \mathrm{Ca}$ and $\mathrm{Mg}$. NJS and NJT had no statistically significant difference in the levels of most organic compounds and inorganic contaminants $(p>0.05)$, but the metals $\mathrm{Na}, \mathrm{Mg}$ and $\mathrm{K}$ were effectively removed in the drinking water treatment plant $(p<0.05)$, which agrees with previous studies (Sun et al. 2011; Zhang et al. 2011a; Chen et al. 2012).

During the animal exposure, average water intake of each mouse was $5.75 \pm 0.17 \mathrm{~g} \mathrm{~d}^{-1}$ in NJS group, $5.17 \pm 0.40 \mathrm{~g} \mathrm{~d}^{-1}$ in NJT group and $5.86 \pm 0.34 \mathrm{~g} \mathrm{~d}^{-1}$ in control group. After exposure for 90 days, liver weight index was $0.039 \pm 0.003$ in NJS group, $0.038 \pm 0.004$ in NJT group and $0.038 \pm 0.003$ in the control group. The water consumption and liver weight index showed no significant difference among the three mice groups $(p<0.05)$. This is supported by Zhang et al. (2011c) indicating that chronic exposure to the drinking water from Yangtze River cannot cause obvious changes in water consumption and body/organ weight of mice. Previous studies also showed that feeding mice with Taihu Lake (China) water posed no significant effect on water intake and body weight (Zhang et al. 2011b; Qin et al. 2012). Although the trace-level pollutants in Yangtze River water cannot obviously affect mice survival and growth, it has been indicated that exposure to the water may disturb hepatic mRNA expression of many genes involved in carcinogenesis (Zhang et al. 2011a; Sun et al. 2011) and reproductive toxicity (Zhao et al. 2009).

\section{Alteration of biological pathways and related gene expression}

Hepatic genomic expression profiles of the mice were analyzed using DNA microarray. Figure 1 shows the distribution of DEGs within different ranges of fold change. A

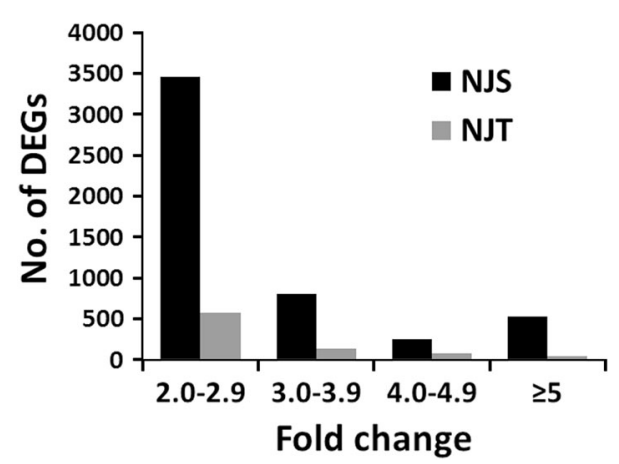

Fig. 1 Distribution of differentially expressed genes (DEGs) in different ranges of fold changes after the mice were exposed to the source water (NJS) and drinking water (NJT) of Yangtze River (China) total of 5,042 in NJS group and 828 genes in NJT group were found to be significantly up-regulated or down-regulated. Among the DEGs of NJS group, most had the fold change within 2.0-2.9 (68.6\%) and 3.0-4.9 (20.9\%), and $10.5 \%$ of the genes had the fold change over 5.0. Similarly, in NJT group, 69.7, 25.7 and $4.6 \%$ of the DEGs were located in the fold ranges of $2.0-2.9,3.0-4.9$ and $\geq 5$, respectively.

KEGG annotation showed that 307 DEGs of NJS group and 31 DEGs of NJT group were classified into 13 and 5 function categories, respectively (Fig. 2). The DEGs in NJS were mostly involved in lipid metabolism (51 genes), followed by neurodegenerative diseases (47 genes), energy metabolism (41 genes) and endocrine system (38 genes) (Fig. 2a). NJT exposure was found to affect lipid metabolism (14 DEGs), xenobiotics biodegradation and metabolism (6 DEGs), cofactor and vitamin metabolism (5 DEGs), endocrine system (5 DEGs) and amino acid metabolism (4 DEGs) (Fig. 2b). Detailed information about the DEGs involved in the function categories is listed in the Supplementary Material Tables S1 and S2. Shi et al. (2012) have indicated that exposure to Yangtze River water poses no obvious hepatotoxicity on mice, but can induce mRNA and protein expression of several pathways including peroxisome proliferator-activated receptors (PPAR) signaling pathway, fatty acid metabolism and unsaturated fatty acid biosynthesis. This hypothesis is supported by a metabolomics study suggesting that the drinking water from Yangtze River can induce liver dysfunction characterized by disorder of branched-chain amino acid and energy metabolism, as well as perturbation of glucose-alanine cycle (Zhang et al. 2011c). Moreover, expression of hepatic mRNA involved in cancer genesis and development was also found to be altered in the mice fed with the river water (Zhang et al. 2011a; Sun et al. 2011).

Alteration of lipid metabolism and other biological processes

GO annotation showed that 1,119 DEGs in NJS group and 49 DEGs in NJT group were involved in 131 (6 categories) and 17 (3 categories) biological processes, respectively (Fig. 3), indicating that NJS exerted greater influence on biological processes of the mice. NJS exposure seemed to mainly affect metabolic process (703 DEGs), biosynthetic process (154 DEGs), transport process (277 DEGs), response process (32 DEGs) and localization process (159 DEGs), and NJT exposure induced differential expression of the genes involved in biosynthetic process (10 genes) and metabolic process (31 genes) (Supplementary Material Tables S3 and S4). 
Fig. 2 Functional grouping of differentially expressed genes involved in metabolic pathways of the mice exposed to the source water (a) and drinking water (b). The genes were functionally categorized according to KEGG pathway database through enrichment analysis on biological pathways. A $p<0.05$ was considered statistically significant

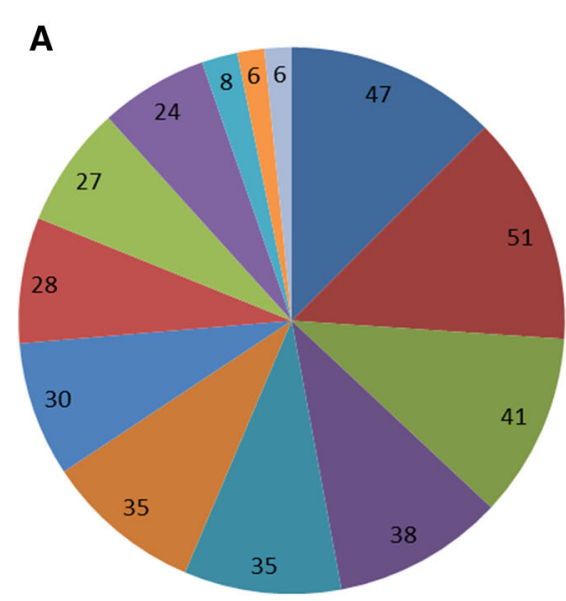

neurodegenerative Diseases

- Lipid Metabolism

Energy Metabolism

- Endocrine System

- Transport and Catabolism

- Translation

- Carbohydrate Metabolism

amino Acid Metabolism

- Nucleotide Metabolism

- Glycan Biosynthesis and Metabolism

- Metabolism of Terpenoids and Polyketides

घ Metabolism of Cofactors and Vitamins

Environmental Adaptation

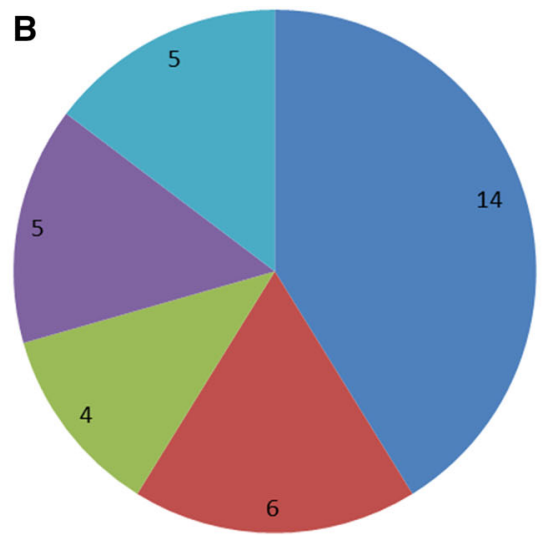

- Lipid Metabolism

- Xenobiotics Biodegradation and Metabolism

Amino Acid Metabolism

Metabolism of Cofactors and Vitamins

Endocrine System
Interestingly, many of the DEGs in NJS and NJT groups were closely related to the interconnected lipid metabolic processes, including cholesterol biosynthetic process (GO: 0006695), cholesterol metabolic process (GO: 0008203), steroid biosynthetic process (GO: 0006694), sterol metabolic process (GO: 0016125), sterol biosynthetic process (GO: 0016126), steroid metabolic process (GO: 0008202) and lipid biosynthetic process (GO: 0008610) (Fig. 4). Presence of various pollutants including PAEs and PAHs in NJS and NJT might be responsible for the lipid metabolic disturbance, which is confirmed by previous studies demonstrating that PAEs had a significant impact on rat lipid metabolism (Dai et al. 2006; $\mathrm{Xu}$ et al. 2006). PAEs are considered as an important group of environmental endocrine disruptors (Wong and Gill 2002; Lee and Koo 2007), which can also induce down-regulation of genes in the steroidogenesis pathway and lipid/sterol/cholesterol transport pathway (Euling et al. 2011). Additionally, in vivo (Kawano et al. 2010) and in vitro (Podechard et al. 2012) studies have indicated that PAHs exposure can induced lipid accumulation or steatosis in animal cells.
DEGs related to lipid metabolic disturbance

Since KEGG and GO annotations consistently indicated that most of the DEGs were involved in lipid metabolism, we further explored the potential molecular mechanisms of the lipid metabolism disturbance. The DEGs were found to be involved in 6 lipid metabolic pathways including fatty acid metabolism, glycerophospholipid metabolism, unsaturated fatty acid biosynthesis, steroid biosynthesis, primary bile acid biosynthesis and steroid hormone biosynthesis (Fig. 5). Interestingly, these KEGG pathways could be grouped into two maps. One map included fatty acid metabolism, glycerophospholipid metabolism and unsaturated fatty acid biosynthesis (Fig. 6), and the other included steroid biosynthesis, primary bile acid biosynthesis and steroid hormone biosynthesis (Fig. 7).

In the map of fatty acid metabolism, unsaturated fatty acid biosynthesis and glycerophospholipid metabolism (Fig. 6), NJS and NJT exposure significantly altered mRNA expression of 43 and 4 genes, respectively, revealing that NJS posed greater effect on lipid metabolism than NJT. The DEGs of fatty acid metabolism and unsaturated fatty acid 

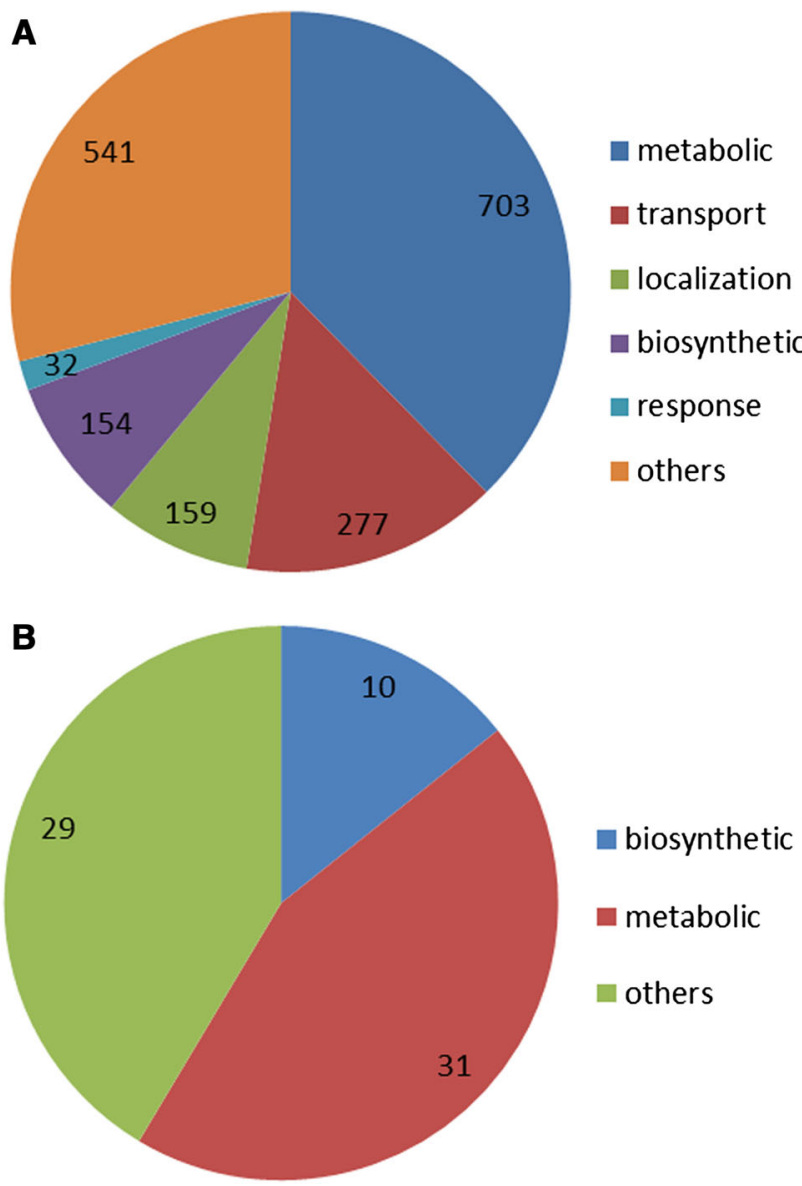

Fig. 3 Functional grouping of differentially expressed genes involved in biological processes of the mice exposed to the source water (a) and drinking water (b). The genes were functionally categorized according to GO pathway database. A $p<0.05$ was considered statistically significant

biosynthesis were found to encode acyl-CoA thioesterases (Acot1, Acot2, Acot3 and Acot4), acyl-CoA oxidases (Acox3), aldehyde dehydrogenases (Aldh1b1, Aldh2, Aldh3a2 and Aldh9a1), acyl-CoA dehydrogenases (Acads

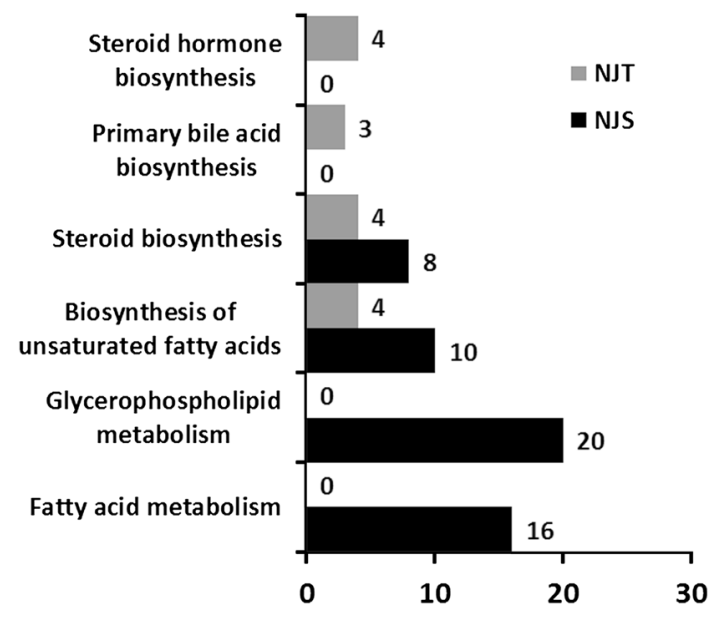

Fig. 5 Differentially expressed genes in NJS (source water) group (black) and NJT (drinking water) group (gray) in different lipid metabolic pathways including fatty acid metabolism, glycerophospholipid metabolism, unsaturated fatty acid biosynthesis, steroid biosynthesis, primary bile acid biosynthesis and steroid hormone biosynthesis. The genes were functionally categorized according to KEGG pathway database. A $p<0.05$ was considered statistically significant

and Acadsb), long-chain fatty acid CoA ligases (Acsl3 and Acs14) and acetyl-CoA acyltransferases (Acaa1a and Acaalb). Acsl3 and Acsl4 can convert free long-chain fatty acids into fatty acyl-CoA esters (Mashek et al. 2005), and acyl-CoA thioesterases subsequently hydrolyze CoA esters to free acid and CoA along with dehydrogenation of acylCoA derivatives by acyl-CoA dehydrogenases (Hunt et al. 2005). Aldehyde dehydrogenases are thought to play a major role in the oxidation of long-chain aliphatic aldehydes to fatty acid (Marchitti et al. 2008). Acyl-CoA thioesterases and acetyl-CoA acyltransferases are often regulated by PPAR, and Acox 3 are involved in the desaturation of 2-methyl branched fatty acids in the peroxisomes (Vanhove et al. 1993). Recently, Shi et al. (2012) have indicated that feeding mice with Yangtze River water can
Fig. 4 Differentially expressed genes in NJS (source water) group (black) and NJT (drinking water) group (gray) in different biological processes including cholesterol biosynthesis, cholesterol metabolism, steroid biosynthesis, sterol metabolism, sterol biosynthesis, steroid metabolism and lipid biosynthesis. The genes were functionally categorized according to GO pathway database. A $p<0.05$ was considered statistically significant

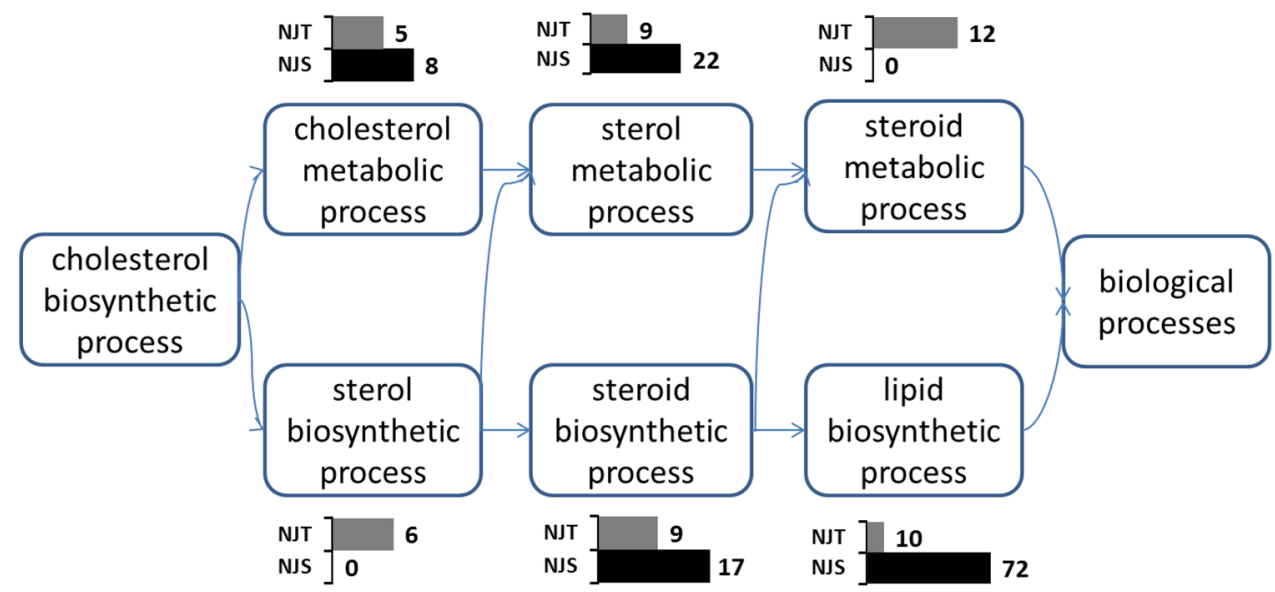




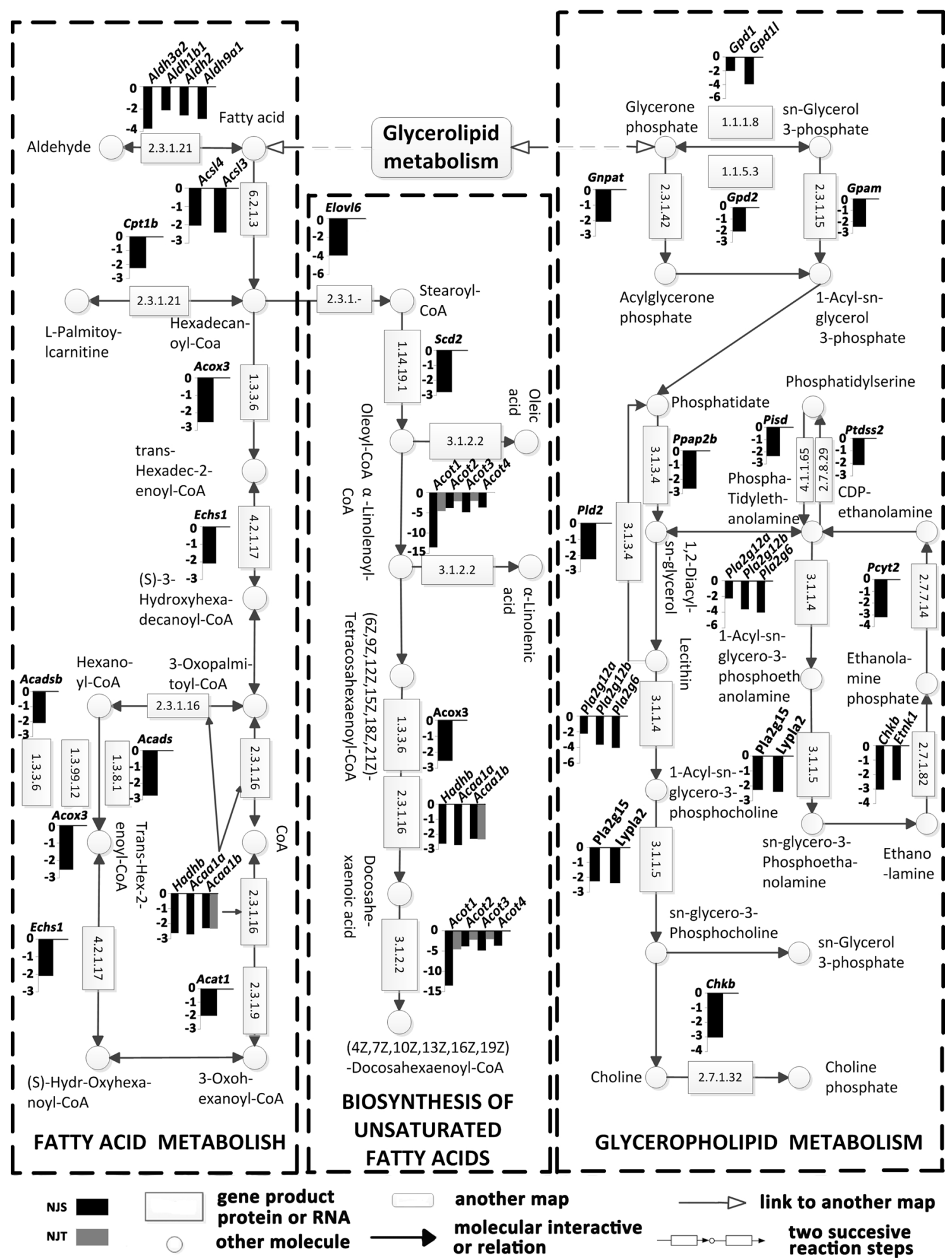

Fig. 6 Mapping of differentially expressed genes in the metabolic pathways of fatty acid metabolism, glycerophospholipid metabolism and unsaturated fatty acid biosynthesis in the mice exposed to the source water (NJS) and drinking water (NJT)

affect hepatic PPAR activities, indicating that the lipid metabolism disturbance induced by the river water exposure may be mediated by PPAR activation.
In the pathway of glycerophospholipid metabolism, NJS and NJT exposure inhibited mRNA expression of the dehydrogenases (Gpd1, Gpd11 and Gpd2) and 


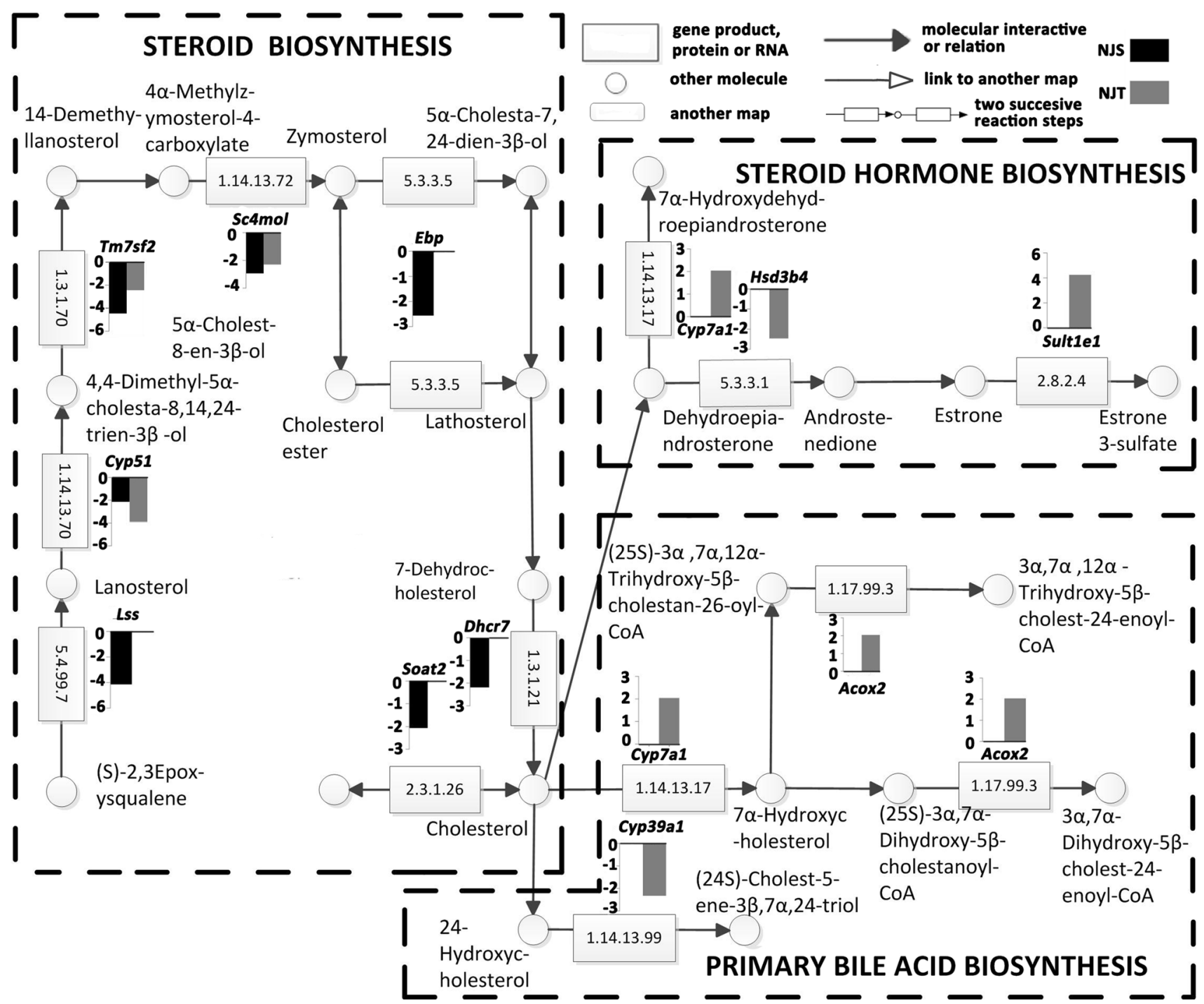

Fig. 7 Mapping of differentially expressed genes in the metabolic pathways of steroid biosynthesis, primary bile acid biosynthesis and steroid hormone biosynthesis in the mice exposed to the source water (NJS) and drinking water (NJT)

acyltransferases (Gnpat and Gpam) capable of catalyzing transformation of glycerol phosphate to 1-acyl-sn-glycerol phosphate (Fig. 6). The activity of phosphatidic acid phosphatase family (Pla2g6, Pla2g12a, Pla2g12b and Pla2g15) was subsequently suppressed, and the enzymes are able to convert phosphatidic acid to diacylglycerol and function in de novo synthesis of glycerolipids (Carman and Han 2009). Little information is available about the effect of environmental toxicants on the pathway of glycerophospholipid metabolic pathway, but Modi et al. (2008) revealed that cadmium could suppress the pathway to influence lipid/ phospholipid makeup in rat liver. More recently, Zhang et al. (2013) have revealed that trichloroacetamide, a common disinfection byproduct often generated by chlorination of drinking water, can disturb expression of 4 genes involved in glycerophospholipid metabolism in mice livers.
In the map of fatty acid steroid biosynthesis, primary bile acid biosynthesis and steroid hormone biosynthesis (Fig. 7), the DEGs were found to encode cytochrome P450 enzymes (Cyp7a1, Cyp39a1 and Cyp51), hydroxy-steroid dehydrogenases (Hsd3b4 and Hsd3b5), transmembrane 7 superfamily (Tm7sf2), sterol $O$-acyltransferases (Soat2), emopamil binding proteins (Ebp), dehydrocholesterol reductases (Dhcr7), acyl-CoA oxidases (Acox2), lanosterol synthases (Lss) and methyl sterol oxidase ( $\mathrm{Sc} 4 \mathrm{~mol}$ ). This study showed that NJT posed more evident effect on the pathways of primary bile acid biosynthesis and steroid hormone biosynthesis than NJS, since all the DEGs in the pathways arose from NJT exposure. NJT exposure induced differential expression of Cyp7b1 and Hsd3b4, which may affect bile acid and steroid biosynthesis (Gant et al. 2003). P450 proteins can catalyze many reactions involved in 
synthesis of cholesterol and steroids (Pelkonen et al. 2008), and the presence of PAHs (Yamaori et al. 2012), PAEs (Ozaki et al. 2006) and metals (Pelkonen et al. 2008) in Yangtze River water might result in the differential mRNA expression of $\mathrm{P} 450$ proteins. It should be indicated that generation of disinfection byproducts in the chlorinated drinking water might also contribute to the protein expression alteration induced by NJT (Zhang et al. 2013).

Although the water samples were found to contain 11 organic compounds and 12 inorganic contaminants, a number of pollutants not tested in this study may also exit in the samples. The contaminated drinking water was found to exert joint effects on lipid metabolism, but the major contaminants affecting lipid metabolism cannot be determined by statistical correlation analyses due to the presence of various pollutants in the drinking water and the availability of data from only three groups of mice. Toxic effects of the individual chemicals and more water samples should be evaluated in future to confirm the responses of lipid metabolism to the source water and drinking water containing various pollutants.

\section{Conclusion}

This study investigated hepatic transcriptional profile of mice fed with the source water and tap water from a drinking water treatment plant by using DNA microarray. Various trace-level pollutants including PAEs, PAHs and metals were present in the water, which induced differential expression of a number of genes in the mice livers. The exposure also affected several metabolic pathways and biological processes, among which lipid metabolism mediated by 6 metabolic pathways was most susceptible to both the source water and drinking water. Although the water consumption might cause no obvious liver tissue damages, the lipid metabolic disturbance induced by the trace-level pollutants should receive public health concern. This is the first study investigating the effect of drinking water on mRNA expression of the genes involved in hepatic lipid metabolism. Future work may also include confirmation of the toxicological effects by epidemiological investigation and exploration of the molecular mechanism through in vitro exposure assays.

Acknowledgments This study was financially supported by National Natural Science Foundation of China (No. 51290282 and 51278240).

\section{References}

Axmon A, Rylander L, Rignell-Hydbom A (2008) Reproductive toxicity of seafood contaminants: prospective comparisons of
Swedish east and west coast fishermen's families. Environ Health 7:1-10

Bechmann LP, Hannivoort RA, Gerken G, Hotamisligil GS, Trauner M, Canbay A (2012) The interaction of hepatic lipid and glucose metabolism in liver diseases. J Hepatol 56(4):952-964

Carman GM, Han GS (2009) Phosphatidic acid phosphatase, a key enzyme in the regulation of lipid synthesis. J Biol Chem 284:2593-2597

Chen YJ, Zhang XX, Wu B, Liu B, Xiao L, Li AM, Cheng SP (2012) Semivolatile organic compounds removal and health risk reduction in drinking water treatment biofilters applying different backwashing strategies. Int J Environ Sci Technol 9:661-670

Currie RA, Orphanides G, Moggs JG (2005) Mapping molecular responses to xenoestrogens through Gene Ontology and pathway analysis of toxicogenomic data. Reprod Toxicol 20:433-440

CWRC (Changjiang Water Resources Commission) (2011) Report on water resources in the Yangtze River. Available at http://202. 103.33.45:8380/templet/default/ShowArticle.jsp?id=3348 on 10 Jan 2013

Dai GD, Cui LB, Song L, Liu R, He J, Wang YB, Cheng JF, Chang HC, Wang XR (2006) Effects of terephthalic acid on rat lipid metabolism. Biomed Environ Sci 19:273-276

Euling SY, White LD, Kim AS, Sen B, Wilson VS, Keshava C, Keshava N, Hester S, Ovacik AM, Ierapetritou MG, Androulakis IP, Gaido KW (2011) Use of genomic data in risk assessment case study: II. Evaluation of the dibutyl phthalate toxicogenomic data set. Toxicol Appl Pharmacol 271(3):249-262

Gant TW, Baus PR, Clothier B, Riley J, Davies R, Judah DJ, Edwards RE, George E, Greaves P, Smith AG (2003) Gene expression profiles associated with inflammation, fibrosis, and cholestasis in mouse liver after griseofulvin. Environ Health Perspect 111(6):847-853

Hunt MC, Yamada J, Maltais LJ, Wright MW, Podesta EJ, Alexson SE (2005) A revised nomenclature for mammalian acyl-CoA thioesterases/hydrolases. J Lipid Res 46(9):2029-2032

Kawano Y, Nishiumi S, Tanaka S, Nobutani K, Miki A, Yano Y, Seo Y, Kutsumi H, Ashida H, Azuma T, Yoshida M (2010) Activation of the aryl hydrocarbon receptor induces hepatic steatosis via the upregulation of fatty acid transport. Arch Biochem Biophys 504(2):221-227

Keshavarzi B, Moore F, Najmeddin A, Rahmani F, Malekzadeh A (2012) Quality of drinking water and high incidence rate of esophageal cancer in Golestan Province of Iran: a probable link. Environ Geochem Health 34(1):15-26

Kosmehl T, Otte JC, Yang L, Legradi J, Bluhm K, Zinsmeister C, Keiter SH, Reifferscheid G, Manz W, Braunbeck T, Straehle U, Hollert H (2012) A combined DNA-microarray and mechanismspecific toxicity approach with zebrafish embryos to investigate the pollution of river sediments. Reprod Toxicol 33(2):245-253

Kozul-Horvath CD, Zandbergen F, Jackson BP, Enelow RI, Hamilton JW (2012) Effects of low-dose drinking water arsenic on mouse fetal and postnatal growth and development. PLoS One 7(5):e38249

Larregle EV, Varas SM, Oliveros LB, Martinez LD, Anton R, Marchevsky E, Gimenez MS (2008) Lipid metabolism in liver of rat exposed to cadmium. Food Chem Toxicol 46(5):1786-1792

Lee BM, Koo HJ (2007) Hershberger assay for antiandrogenic effects of phthalates. J Toxicol Environ Health A 70:1365-1370

Lin J, Fu C, Zhang X, Xie K, Yu Z (2012) Heavy metal contamination in the water-level fluctuating zone of the Yangtze River within Wanzhou Section, China. Biol Trace Res 145(2):268-272

Maranghi F, Lorenzetti S, Tassinari R, Moracci G, Tassinari V, Marcoccia D, Di VA, Eusepi A, Romeo A, Magrelli A, Salvatore M, Tosto F, Viganotti M, Antoccia A, Di MA, Azzalin G, Tanzarella C, Macino G, Taruscio D, Mantovani A (2010) In utero exposure to di-(2-ethylhexyl) phthalate affects liver 
morphology and metabolism in post-natal CD-1 mice. Reprod Toxicol 29(4):427-432

Marchitti SA, Brocker C, Stagos D, Vasiliou V (2008) Non-P450 aldehyde oxidizing enzymes: the aldehyde dehydrogenase superfamily. Expert Opin Drug Metab Toxicol 4(6):697-720

Mashek DG, Bomfeldt KE, Coleman RA, Berger J, Bernlohr DA, Black P, DiRusso CC, Farber SA, Guo W, Hashimoto N, Khodiyar V, Kuypers FA, Maltais LJ, Nebert DW, Renieri A, Schaffer JE, Stahl A, Watkins PA, Vasiliou V, Yamamoto TT (2005) Revised nomenclature for the mammalian long-chain acyl-CoA synthetase gene family. J Lipid Res 45(10):1958-1961

Modi HR, Patil N, Katyare S (2008) Effect of treatment with cadmium on kinetic properties of $\mathrm{Na}^{+}, \mathrm{K}^{+}$-ATPase and glucose6-phosphatase activity in rat liver microsomes: a correlative study on influence of lipid/phospholipid make-up. Toxicology 254(1-2):29-41

Nguyen P, Leray V, Diez M, Serisier S, Le Bloćh J, Siliart B, Dumon H (2008) Liver lipid metabolism. J Anim Physiol Anim Nutr 92(3):272-283

Oh JH, Moon HB, Choe ES (2012) Alterations in differentially expressed genes by exposure to a mixture of carcinogenic polycyclic aromatic hydrocarbons in the liver of Oryzias latipes. Environ Toxicol Pharmacol 33(3):403-407

Ozaki H, Kitamura S, Sugihara K, Ohta S (2006) Inhibitory effect of phthalate diesters on the cytochrome P450 system. Drug Metab Rev 38(3): 123

Pelkonen O, Turpeinen M, Hakkola J, Honkakoski P, Hukkanen J, Raunio H (2008) Inhibition and induction of human cytochrome P450 enzymes: current status. Arch Toxicol 82(10):667-715

Podechard N, Tekpli X, Catheline D, Holme JA, Rioux V, Legrand P, Rialland M, Fardel O, Lagadic-Gossmann D, Lecureur V (2012) Mechanisms involved in lipid accumulation and apoptosis induced by 1-nitropyrene in Hepalc1c7 cells. Toxicol Lett 206(3):289-299

Qin WD, Yang LY, Zhang XX, Zhang ZY, Xu LZ, Wu J, An J, Wang YP (2012) Cyanobacteria-blooming water samples from Lake Taihu induce endoplasmic reticulum stress in liver and kidney of mice. Ecotoxicology 21:1495-1503

Rebola M, Silva MJ, Antunes AM, Jose SS, Silva ZI, Cardoso AS (2011) Contribution to risk assessment of chlorinated polycyclic aromatic hydrocarbons associated with drinking water chlorination: formation, occurrence and genotoxic effects. Eur J Public Health 20(1):175

Shi P, Zhang XX, Zhang ZY, Zhang Y, Wu B, Cheng SP, Li AM (2012) Chronic exposure to contaminated drinking water stimulates PPAR expression in mice livers. Chemosphere 88(4):407-412

Silverio R, Laviano A, Fanelli FR, Seelaender M (2012) L-Carnitine induces recovery of liver lipid metabolism in cancer cachexia. Amino Acids 42(5):1783-1792

Sun J, Cheng SP, Li AM, Zhang R, Wu B, Zhang Y, Zhang XX (2011) Integration of gene chip and topological network techniques to screen a candidate biomarker gene (CBG) for predication of the source water carcinogenesis risks on mouse Mus musculus. Ecotoxicology 20:1026-1032

Vanhove GF, Van Veldhoven PP, Fransen M, Denis S, Eyssen HJ, Wanders RJ, Mannaerts GP (1993) The CoA esters of 2-methyl- branched chain fatty acids and of the bile acid intermediates diand trihydroxycoprostanic acids are oxidized by one single peroxisomal branched chain acyl-CoA oxidase in human liver and kidney. J Biol Chem 268(14):10335-10344

Welsch F, Nemec MD, Lawrence WB (2008) Two-generation reproductive toxicity study of resorcinol administered via drinking water to $\mathrm{Crl}: \mathrm{CD}(\mathrm{SD})$ rats. Int J Toxicol 27:43-57

Wong JS, Gill SS (2002) Gene expression changes induced in mouse liver by di(2-ethylhexyl) phthalate. Toxicol Appl Pharmacol 185:180-196

Wu B, Cheng SP, Li YQ, Kong J, Zhao DY, Zhang Y, Zhang XX (2009) Transcriptional toxicity of the Yangtze River source water on mouse (Mus musculus) detected by cDNA microarray. Ecotoxicology 18:715-721

Xu Y, Knipp GT, Cook TJ (2006) Effects of di-(2-ethylhexyl)phthalate and its metabolites on the lipid profiling in rat HRP-1 trophoblast cells. Arch Toxicol 80(5):293-298

Yamaori S, Koeda K, Kushihara M, Hada Y, Yamamoto I, Watanabe $\mathrm{K}$ (2012) Comparison in the in vitro inhibitory effects of major phytocannabinoids and polycyclic aromatic hydrocarbons contained in marijuana smoke on cytochrome P450 2C9 activity. Drug Metab Pharmacokinet 27(3):294-300

Yang H, Zhuo S, Xue B, Zhang C, Liu W (2012) Distribution, historical trends and inventories of polychlorinated biphenyls in sediments from Yangtze River Estuary and adjacent East China Sea. Environ Pollut 169:20-26

Yi YJ, Zhang SH (2012) Heavy metal (Cd, Cr, Cu, Hg, Pb, Zn) concentrations in seven fish species in relation to fish size and location along the Yangtze River. Environ Sci Pollut Res 19(9):3989-3996

Zhang WG, Feng H, Chang JN, Qu JG, Xie HX, Yu LZ (2009) Heavy metal contamination in surface sediments of Yangtze River intertidal zone: an assessment from different indexes. Environ Pollut 157:1533-1543

Zhang ZY, Ma LP, Zhang XX, Li WX, Zhang Y, Wu B, Yang LY, Cheng SP (2010) Genomic expression profiles in liver of mice exposed to purified terephthalic acid manufacturing wastewater. J Hazard Mater 181:1121-1126

Zhang R, Cheng SP, Li AM, Sun J, Zhang Y, Zhang XX (2011a) Genome-wide screening of indicator genes for assessing the potential carcinogenic risk of Nanjing City drinking water. Ecotoxicology 20:1033-1040

Zhang Y, Li WX, Zhang R, Sun J, Wu B, Zhang XX, Cheng SP (2011b) Preliminary evaluation of gene expression profiles in liver of mice exposed to Taihu Lake drinking water for 90 days. Ecotoxicology 20:1071-1077

Zhang Y, Wu B, Zhang XX, Li AM, Cheng SP (2011c) Metabolic profiles in serum of mouse after chronic exposure to drinking water. Hum Exp Toxicol 30(8):1088-1095

Zhang Y, Zhang ZY, Zhao YP, Cheng SP, Ren HQ (2013) Identifying health effects of exposure to trichloroacetamide using transcriptomics and metabonomics in mice (Mus musculus). Environ Sci Technol 47:2918-2924

Zhao DY, Cheng SP, Wu B, Zhang Y, Zhang XX, Li WX, Cui Y (2009) Toxicity of the Yangtze River source of drinking water on reproductive system of male mice (Mus musculus). Ecotoxicology 18:729-735 